\title{
Geophysical Investigation of Ground Water Using Vertical Electrical Sounding and Seismic Refraction Methods
}

\author{
M.O Ehigiator ${ }^{1}$, Philomina Okanigbuan ${ }^{2}$ \\ Benson Idahosa University, GRA Benin City, Nigeria \\ ${ }^{1}$ mehigiator@biu.edu.ng, ${ }^{2}$ pokanigbuan@biu.edu.ng
}

\begin{abstract}
Identification of aquiferous zone, their geo-electrical characteristics and the delineation of ground water as an aid to evaluate where bedrock would be conveniently established in Ibusa in Delta State; were carried out.. Two vertical Electrical soundings (VES) using Schlumberger electrode configurations were carried out in Ibusa (Ezuku) in Delta State. They were interpreted with computer iteration. Interpretation of the two VES courses obtained gave a five to six layered earth of the study area. The resistivity of the first layer (weathered zone) ranges between $59.76 \Omega \mathrm{m}$ and $100.500 \Omega \mathrm{m}$. The resistivity of the second layer ranges between $140.10 \Omega \mathrm{m}$ and $714.50 \Omega \mathrm{m}$ and has an average depth of $12 \mathrm{~m}$. Resistivity of the third layer ranges between $125.50 \Omega \mathrm{m}$ and $92.87 \Omega$ mand has an average depth of $72 \mathrm{~m}$. The resistivity of the fourth layer ranges between $405.70 \Omega \mathrm{m}$ and $865.50 \Omega \mathrm{m}$ and has an average depth of $23.7 \mathrm{~m}$. The resistivity of the fifth layer ranges between $307.20 \Omega \mathrm{m}$ and $428.30 \Omega \mathrm{m}$, with an average depth of $51.07 \mathrm{~m}$. The resistivity of sixth layer ranges between $728.80 \Omega \mathrm{m}$ and $1683.00 \Omega \mathrm{m}$. Seismic refraction survey, aimed at delineating the geological structures, was carried out for both geologic and hydro-geologic significance. This method was used to detect the signal to noise ratio in the study area using seismic refraction method, the depths were found to be low compared with the depths from activity method. No aquifer was found in the study areas; as a result, it would be advisable to have a wider spread of cables while carrying out further researches in this area.
\end{abstract}

Keywords: Acquiferous zone, Geo-electrical, Vertical Electrical Soundings, Seismic refraction.

\section{INTRODUCTION}

According to the Encarta Dictionary (2008), ground water is defined as water held from underground in soil or permeable rock, often feeding springs and wells. Ground water is characterized by a certain number of parameters which are determined by geophysical methods such as Electrical methods, Seismic methods, Magnetic methods, Gravity methods (Dobrin, 1983). It is the source of about 40 percent of the water used for different purposes. It is used for domestic, agriculture and it provides 26 percent of industries' needs (Edwards, et al. 1993). Electrical resistivity methods is one of the most useful techniques in underground water geophysical exploration because the resistivity of rock is very sensitive to its ionic contentwhile the seismic methods have been used to delineate bedrock aquifer and fractured rock systems. Electrical Resistivity methods in geophysical exploration for groundwater in a sedimentary environment have proven reliable (Emenike, 2001).

\section{THEORY OF RESISTIVITY}

\subsection{Two-Layer Case with Horizontal Interface}

Let a weathered layer with velocity $\mathrm{V}_{0}$ be underlain by a consolidated layer with velocity $\mathrm{V}_{1}$. The Velocity $\mathrm{V}_{0}$ is sometimes called weathering velocity $\left(\mathrm{V}_{\mathrm{w}}\right)$ while the velocity $\mathrm{V}_{1}$ is sometimes called the consolidated or elevation velocity $\mathrm{V}_{\mathrm{e}}$. The critical distance $\mathrm{X}_{\mathrm{c}}$, sometimes called crossover is defined as the offset at which a refracted event (rather than surface wave) becomes the first break. The critical angle, $i_{c}$ is the angle of incidence for which the refracted ray grazes the surface of the contact between two media of different velocities (Osemeikhian and Asokhian, 1984).

The total time $\mathrm{T}$ along the refraction path $\mathrm{ABCD}$ figure 1 is given by:

$T=T_{A B}+T_{B C}+T_{C D} \frac{Z}{V_{0}} \operatorname{Cos} I C+\left(\frac{x-2 Z \tan I C}{V_{1}}\right)+\frac{Z}{V_{0} \operatorname{Cos} I C}$

$=\frac{2 Z \operatorname{Cos} I C}{V_{0}}-\frac{2 Z \operatorname{Sin} I C}{V_{1} \operatorname{Cos} I C}+\frac{X}{V_{1}}$ 
Noting that $\sin \theta=\frac{v_{1}}{V_{2}}$ (snells law $)$

Since $\frac{\sin i}{\sin r}=\frac{V_{0}}{V_{1}}$, where $\sin r=\sin 90^{\circ}=1$

$\therefore \operatorname{Sin} i=\frac{V_{0}}{V_{1}}$

Also $\operatorname{Sin}^{2} \theta+\operatorname{Cos}^{2} \theta=1$

$\operatorname{Cos}^{2} \theta=1-\operatorname{Sin}^{2} \theta$

$\operatorname{Cos}=\left(1-\operatorname{Sin}^{2} \theta\right)^{1 / 2}=\left(1-v_{0}^{2} / v_{1}^{2}\right)^{1 / 2}$

Cst $0\left(1-v_{0}^{2} / v_{1}^{2}\right)^{1 / 2}$

$\therefore T=\frac{x}{V_{1}}+\frac{2 Z\left(v_{1}^{2}-v_{0}^{2}\right)^{1 / 2}}{v_{1} v_{0}}$ intercept time

The depth $\mathrm{z}$ can be calculated in terms of $\mathrm{X}_{\mathrm{C}}$ by making use of the fact that the time $\mathrm{T}_{0}$ for the "direct wave" to reach $X_{C}$, given by $T_{0}=x / v_{0}$ and the intercept time $T_{i}$ for the refracted wave to reach $X_{C}$, is given by

$\mathrm{T}_{\mathrm{i}}=\mathrm{x} / \mathrm{v}_{1}+2 \mathrm{z}\left(\mathrm{v}_{1}^{2}-\mathrm{v}_{0}^{2}\right)^{1 / 2}\left(\mathrm{v}_{1} \mathrm{v}_{0}\right)$.

$\frac{X_{C}}{V_{0}}-\frac{X_{x}}{V_{1}}+2 Z\left(V_{1}^{2}-V_{0}^{2}\right) /\left(V_{1} V_{0}\right)$

And $z=\left(V_{0} V_{1} X_{c}\left(\frac{1}{V_{0}}-\frac{1}{V_{1}}\right)\right) / 2\left(V_{1}^{2}-V_{0}^{2}\right)^{1 / 2}$

$X_{c}\left(V_{1}-V_{0}\right)^{1 / 2} / 2\left(V_{1}+V_{0}\right)^{1 / 2}$

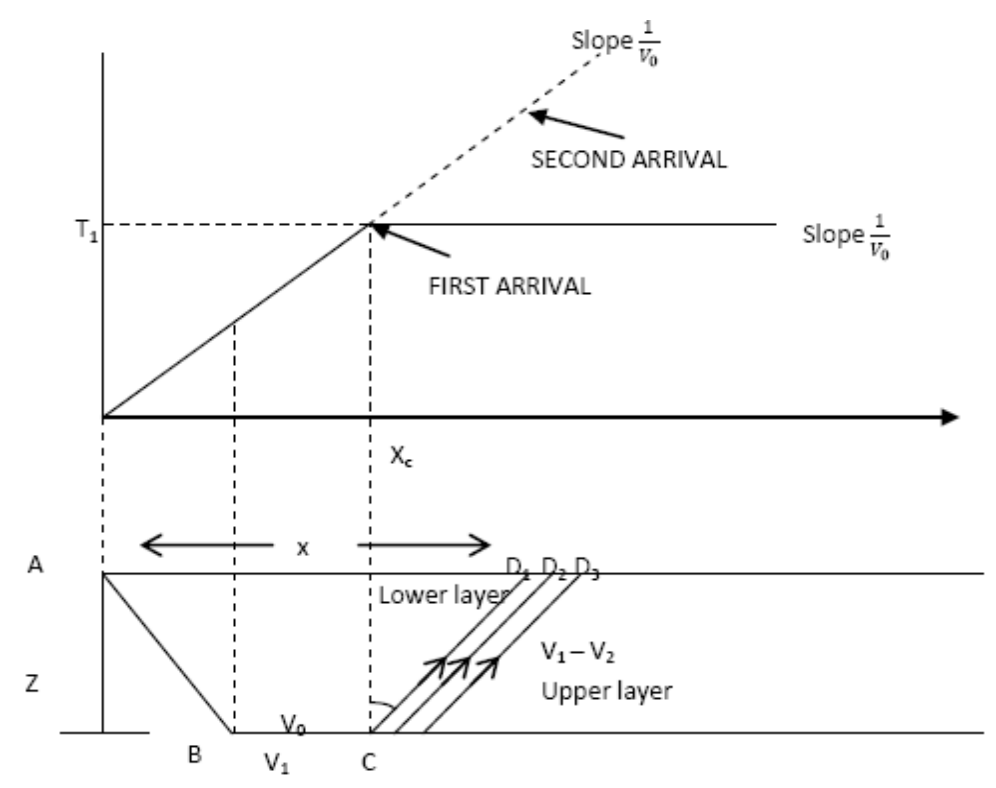

Figure1. Refraction ray paths through 2-layered earth are equal at $X_{c}$. Therefore we have

\section{GEOLOGY OF THE STUDY AREA}

The study area is located within the vegetation area of the Niger Delta. The area is Ibusa which is in Oshimili North Local Government area of Delta State in Nigeria. It lies between latitude $6^{0} 10^{\prime}$ and $6^{0}$ 11'. Ibusa is bounded by Asaba town in the East, Ogwashiuku town in the West, Okpanam in the North and Achala-Ibusa in the South as the boundary towns. The study area is part of Niger Delta. It is mainly sandy soil and does not contain rocks so it is not a basement complex. The ground over there is usually hard and mostly filled with laterite. Borehole has been drilled there before and though now, and sometimes most boreholes drilled there are not successful due to lack of pre-knowledge of the hydro geologic problems. Among the successful ones are those drilled at fire service location. 


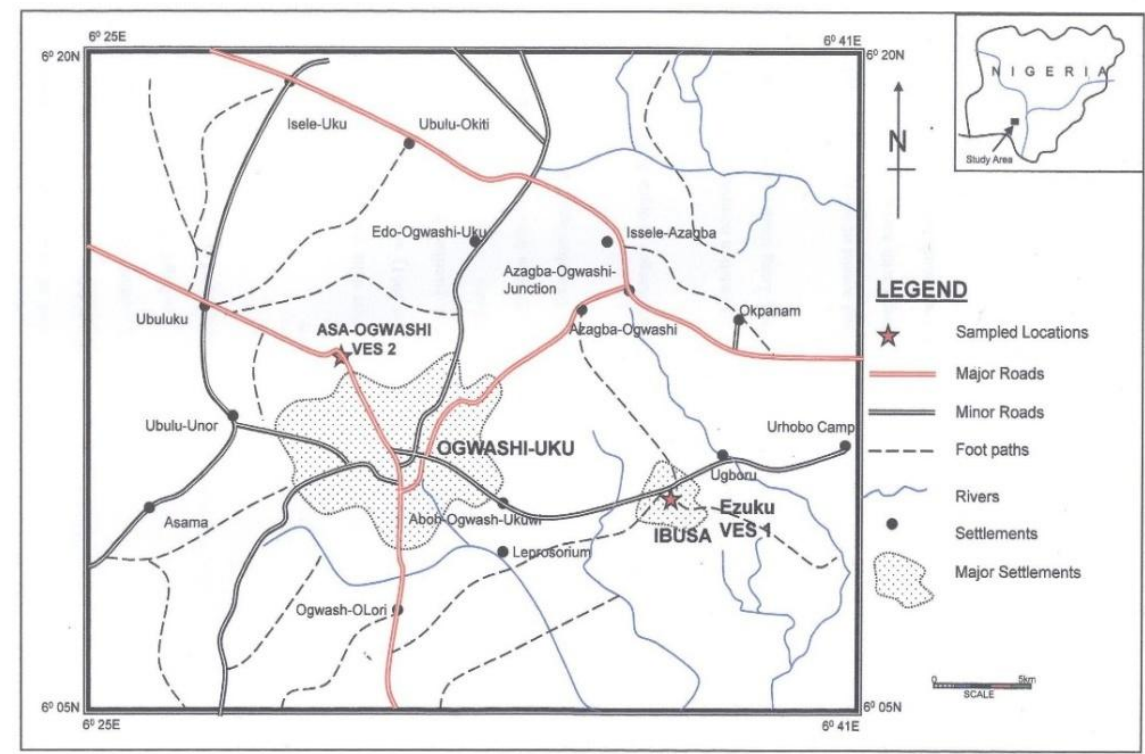

Figure2. Map of Ogwashi - Uku, Ibusa and Environs showing the sampled Locations

Source: map 71, Federal survey of Nigeria 1977

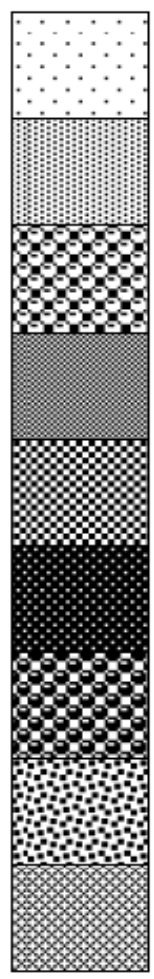

$0 \mathrm{~m}$

$30 \mathrm{~m}$ Lateritic soil

$46 \mathrm{~m}$ Sandy coarse

$67 m$ Sandy clay

91m Fine sand to medium sand

$110 \mathrm{~m}$ Clay

$134 \mathrm{~m}$ Sand

$149 m$ Clay

$168 \mathrm{~m}$ Sand

$180 \mathrm{~m}$ Clay reddish

Figure3. Lithology of Ibusa community in Delta state

\section{Methodology}

The electrical resistivity sounding method employed in this study is the Schlumberger array of the vertical electrical sounding profile method.

The ABEM SAS 300B electrical resistivity equipment was used to observe resistivity responses of the subsurface layers which are recorded in resistance measured in ohm-meter. The two current and potential electrodes were hammered into the ground in accordance with the standard Schlumberger recording street, furthermore, the current electrodes were spread further apart with corresponding potential electrodes spacing. Equipment called terrameter was used to takethe reading at each of the stations after the fourth beep sound. These procedures were repeated for four (4) other VES points in the field. 


\subsection{Seismic Refraction Method}

OYO MCSEIS-160 equipment was used for the recording of the seismic refraction pulses with a chosen field configuration. Twelve (12) Geophones were along in the 12-channel seismic recorder port of the equipment. An offset distance of $3 \mathrm{~m}$ was set from extreme geophone position for both the forward and reverse points. The distances within the geophones 1-12, were in the configuration $2,2,3,3,5,6,5,3,3,2,2$.

The sledge hammer was used as a source of energy to transverse the short recording range (kearey, et al. 1991). With the trigger metal and base metal plate well placed and every other connection intact, a measured offset distance of $100 \mathrm{~m}$ between multicore cable and the geophone positioning (firmly stacked vertically with their spikes to the ground) were established. Besides forward shots were made and seismic refraction pulses were recorded and printed out as hard copy. The entire operation was replaced and the reverse shots were repeated four other times along the specified transverse.

The results obtained from the interpretation techniques used are shown as geo electrical section shown in the table below. The data below were obtained from the seismic operation work in Ibusa area of Delta state.

Table1. Ibusa forward and reverse (EZUKU)

\begin{tabular}{|l|l|l|l|l|l|l|l|l|l|l|l|l|}
\hline GEOPHONE NO & 1 & 2 & 3 & 4 & 5 & 6 & 7 & 8 & 9 & 10 & 11 & 12 \\
\hline GEOPHONE DIST & 3 & 2 & 2 & 3 & 3 & 5 & 6 & 5 & 3 & 3 & 2 & 2 \\
\hline ON GEOPHONE SEP & 3 & 5 & 7 & 10 & 13 & 18 & 24 & 29 & 32 & 35 & 37 & 39 \\
\hline REV GEOPHONE SEP & 39 & 37 & 35 & 32 & 29 & 24 & 18 & 13 & 10 & 7 & 5 & 3 \\
\hline ON TIME (ms) & 12 & 17 & - & 35 & 43 & 49 & 60 & 68 & 73 & 78 & - & 85 \\
\hline REV TIME (ms) & 85 & 78 & - & 72 & 68 & 55 & 48 & 38 & 32 & 23 & - & 18 \\
\hline
\end{tabular}

\subsection{Resistivity Field Record}

Table2. VES (IBUSA)

\begin{tabular}{|l|l|l|}
\hline STATION NUMBER & ELECTRODE AB/2 (m) & APPARENT RESISTIVITY $(\boldsymbol{\Omega m})$ \\
\hline 1 & 1.00 & 71.0 \\
\hline 2 & 1.47 & 85.0 \\
\hline 3 & 2.15 & 96.0 \\
\hline 4 & 3.00 & 110.0 \\
\hline 5 & 4.60 & 121 \\
\hline 6 & 6.80 & 130 \\
\hline 7 & 10.00 & 165 \\
\hline 8 & 14.70 & 181 \\
\hline 9 & 21.50 & 235 \\
\hline 10 & 31.60 & 300 \\
\hline 11 & 46.00 & 315 \\
\hline 12 & 68.00 & 323 \\
\hline 13 & 100.00 & 390 \\
\hline 14 & 147.00 & 500 \\
\hline 15 & 213.00 & 553 \\
\hline 16 & 326.00 & 600 \\
\hline 17 & 464.00 & 700 \\
\hline
\end{tabular}

\section{RESULTS AND DISCUSSION}

\subsection{Resistivity Method}

The characteristic Geo-electrical sections for the study area was mapped. The Geo-electrical section was taken along NW-NE profile, showing a maximum of five to six layered earths of the study areas.

The first layer, which is the weathered zone (Topsoil), has resistivity values ranging between $59.8 \Omega \mathrm{m}$ in VES1 and $100 . \Omega \mathrm{m}$ in VES 2 with a depth of $0.6 \mathrm{~m}$ and $1.2 \mathrm{~m}$. This is the Topsoil. (Laterite soil).

The second layer has resistivity values ranging between $140.1 \Omega \mathrm{m}$ in VES 1 and $714.5 \Omega \mathrm{m}$ in VES 2 with a depth of $1.3 \mathrm{~m}$ and $2.5 \mathrm{~m}$. This layer is brownish sand.

The third layer has resistivity values ranging between $125.5 \Omega \mathrm{m}$ in VES 1 and $92.87 \Omega \mathrm{m}$ in VES 2 with a depth of $5.7 \mathrm{~m}$ and $5.5 \mathrm{~m}$. This layer is fine sand/medium sand. 
The fourth layer has resistivity values ranging between $405.7 \Omega \mathrm{m}$ in VES 1 and $865.5 \Omega \mathrm{m}$ in VES 2 with a depth of $23.0 \mathrm{~m}$ and $24.5 \mathrm{~m}$. This layer is fine sand to medium sand.

The fifth layer has resistivity values ranging between $307.2 \Omega \mathrm{m}$ in VES 1 and 428.3 in VES 2 with a depth of $51.97 \mathrm{~m}$ and $50.17 \mathrm{~m}$. This layer is coarse sand with clay.

The sixth layer has resistivity value of $728.8 \Omega \mathrm{m}$ in VES 1 with a depth of $104.7 \mathrm{~m}$. Layer is clayey sand.

A correlation of the lithology log around the study areas with the geo-electric section shows that the sediments of the various layers $(1,2,3,4,5$ and 6$)$ of the study areas reveals essentially laterite soil (Topsoil), brownish sand, fine sand/medium sand and fine sand medium sand, coarse sand and with clay and clayey sand.

\subsection{Seismic Method}

Comparing the velocities in table 4.5, with the appropriate velocities of the longitudinal wave for representative materials, for the first transverse, IBUSA $(0057,0058)$, the forward and reverse seismic sections were sections recorded and had a velocity range of the first layer as $175 \mathrm{~m} / \mathrm{s}-273 \mathrm{~m} / \mathrm{s}$ and the second layer as $478 \mathrm{~m} / \mathrm{s}-577 \mathrm{~m} / \mathrm{s}$ with an average thickness of $1.5 \mathrm{~m}$. This corresponds to Topsoil (Laterite with clay). This also corresponds to Topsoil (laterite with clay).

The total depth for VES1 IS $93.3 \mathrm{~m}$ and that of VES2 is $99.4 \mathrm{~m}$. Since it has been observed that the lithology and geo-electric section show that the sediments of these areas range from laterite soil (Topsoil), Brownish sand, fine sand/medium sand, fine sand medium sand, and clayey sand there will be a portable water supply. Generally the aquifer unit of the study areas is unconfined.

\section{CONCLUSION}

The Vertical Electrical Sounding (VES) and the seismic investigation of the study areas have provided valuable information on the nature of the sub-surface layers. The geo-electrical section of the study areas shows five to six layered earths and the water bearing formation, (Aquifer).

The profile aquifer can be located as depth beyond $50 \mathrm{~m}$ but most prolific aquifer of the study areas can be related beyond the depth of $104.7 \mathrm{~m}$ with the resistivity values ranging between $728.8 \Omega \mathrm{m}$ to $428.3 \Omega \mathrm{m}$ from the geophysical investigation for the search of groundwater using VES in Ibusa. It has been found or observed that the first layer is the Topsoil (laterite soil), the second layer is the Brownish sand, the third layer is the fine sand/medium sand, the fourth layer is fine sand to medium sand and the fifth layer is clayey sand. Portable groundwater would be available at a depth beyond $104.7 \mathrm{~m}$ in the study areas.

Besides, from the geophysical investigation for the search of groundwater using seismic refraction method in Ibusa, it was discovered that the velocities of the first layer for forward and reverse is $175 \mathrm{~m} / \mathrm{s}-272 \mathrm{~m} / \mathrm{s}$, and the second layer for the forward and reverse is $478 \mathrm{~m} / \mathrm{s}-577 \mathrm{~m} / \mathrm{s}$ with an average thickness of $1.5 \mathrm{~m}$ in Ibusa. While the velocities of the first layer for forward and reverse is $172 \mathrm{~m} / \mathrm{s}$ $273 \mathrm{~m} / \mathrm{s}$ and the second layer for forward and reverse is $492 \mathrm{~m} / \mathrm{s}-645 \mathrm{~m} / \mathrm{s}$ with an average thickness of the layer in Ibusa as 1.81 mdue to the shot-geophone spread, the seismic method was used to determine the nature of the weathered layer from layer velocities which fall under laterite with clay and is regarded as the topsoil (weathered layer). It was observed from the Resistivity and Seismic methods interpretation, that the aquifer zone is beyond $104.7 \mathrm{~m}$.

\section{RECOMMENDATION}

From the results got from VES and Seismic methods, it is important to say that VES method is preferable to seismic method in the study areas, since VES gave plausible values which when correlated with the existing borehole data confirmed the aquifer level spread. Hence for subsequent studies using the seismic refraction method, it is recommendation that the shot-geophone spread should be very large so as to penetrate deeper.

\section{REFERENCES}

Dobrin, M. B. (1983), Introduction to Geophysical Prospecting, Mc Graw-Hill.

Edward, T (1999), The Earcth America. 
Emenike, E.A. (2001), Geophysical Exploration for ground water in a Sedimentary Environment. Global J. Pure Apple, Sci, 7(1): 97-102.

Oseimekhian, J and Asokhia, M.W (1989), Applied Geophysics for Engineers and Geologists, Josamtos, Ltd Printer, Benin City.

\section{AUTHOR's BIOGRAPHY}

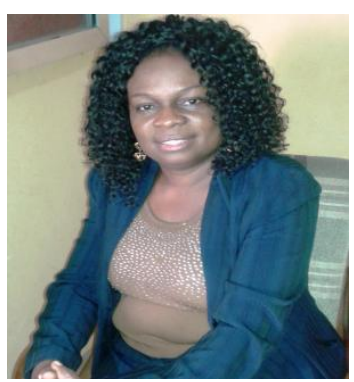

Dr.(Mrs) M.O. Ehigiator, is an Associate professor of Physics (Geophysics) in Benson Idahosa University. She is currently the Head of Department of Basics Sciences, in the Faculty of Basic and Applied Sciences. She is also a Petroleum Engineer where she specialized in Reservoir. She has supervised many students both at undergraduate and postgraduate graduate level. My research interest is in Reservoir and formation Evaluation. 